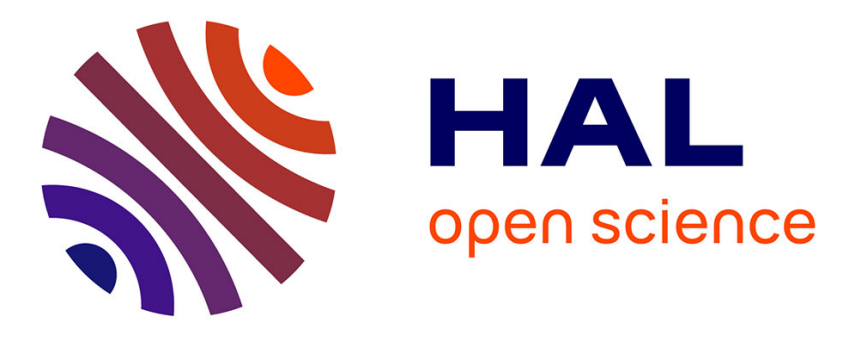

\title{
Interactions of an eddy current sensor and a multilayered structure
}

Thanh Long Cung, Pierre-Yves Joubert, Eric Vourc'H, Pascal Larzabal

\section{To cite this version:}

Thanh Long Cung, Pierre-Yves Joubert, Eric Vourc'H, Pascal Larzabal. Interactions of an eddy current sensor and a multilayered structure. Electronics Letters, 2010, 46 (23), pp.1550-1551. 10.1049/el.2010.2611. hal-00832688

\section{HAL Id: hal-00832688 https://hal.science/hal-00832688}

Submitted on 18 Jul 2013

HAL is a multi-disciplinary open access archive for the deposit and dissemination of scientific research documents, whether they are published or not. The documents may come from teaching and research institutions in France or abroad, or from public or private research centers.
L'archive ouverte pluridisciplinaire HAL, est destinée au dépôt et à la diffusion de documents scientifiques de niveau recherche, publiés ou non, émanant des établissements d'enseignement et de recherche français ou étrangers, des laboratoires publics ou privés. 


\title{
On the interactions of an eddy current sensor and a multilayered structure
}

\author{
T.L. Cung, P.Y. Joubert, E. Vourch and P. Larzabal
}

In this letter, the interactions between a cup-core eddy current sensor and a metallic layered structure is studied. An affine relationship between the sensor normalized impedance and the distance between two plates of a metallic assembly is brought to light both by the experiment and by finite elements computations.

Introduction: The non-destructive evaluation (NDE) of the integrity of conductive parts is a major issue in the manufacturing and in the maintenance of aircrafts, whether for evaluating the geometric parameters of pieces during their manufacturing, or for characterizing the defects appeared inside of service structures. The eddy currents $(E C)$ technique is well suited to such applications since it is easy to implement, sensitive, robust and eco-aware. Moreover, under certain conditions, it allows for characterizing defects [1] or evaluating physical parameters [2] with sufficient accuracy. However, as far as multilayered structures such as aeronautical assemblies are concerned, the NDE is an "ill-posed" problem, the resolution of which is reputed difficult [3]. To solve this problem, several methods based on the analytical model of an air cored coil or based on neural networks have been proposed [4], [5]. In this letter, the authors investigate the relationship between the variations of the normalized impedance of a cup core EC sensor and the distance between 
two electrically conducting parts of a metallic assembly. This study aims at opening the way to the design of simple model-based approaches for the resolution of the NDE inverse problem for any type of EC sensor.

Experimental setup: The NDE problem underlying this study consists in estimating the air gap between two conductive plates, such as a coating fixed on wing ribs or spars, in aeronautical assemblies. In order to experimentally carry out this problem, plates made of an aluminium alloy featuring an electrical conductivity $\sigma=17 \mathrm{MS} / \mathrm{m}$ and a unitary relative magnetic permeability are used. The wing coating is represented by a plate of thickness $c=1.5 \mathrm{~mm}$, whereas the rib, which in practice is a piece of variable thickness, is represented by a series of plates featuring thicknesses $r$ comprised between $1.5 \mathrm{~mm}$ and $25 \mathrm{~mm}$. The variable air gap separating two conductive layers, denoted $a$, created by using insulating sheets featuring both unitary relative magnetic permeability and dielectric permittivity, is comprised in the $0 \mu \mathrm{m}$ to $500 \mu \mathrm{m}$ range. The EC data are acquired by means of a magnetic cup-core coil featuring 110 turns and an outer diameter of $35 \mathrm{~mm}$, placed on the coating without either lift-off or tilt angles, as shown in Figure 1. Its free impedance (obtained when the sensor is placed far away from the target) is equivalent to a resistance $R_{0}=4.6 \Omega$ in series with an inductance $L_{0}=3.04 \mathrm{mH}$. EC data are obtained through the sensor impedance via an impedance analyzer (HP4192A) controlled by a computer. We consider the normalized impedance (NI) denoted $Z_{n}$ and defined in [2] for a harmonic as:

$$
Z_{n}=R_{n}+j \cdot X_{n}=\left(Z_{a}-R_{0}\right) / X_{0}
$$


where $Z_{a}$ is the impedance of the sensor when electromagnetically coupled with a two plate assembly featuring an air gap $a$, and $X_{0}$ is the free reactance of the sensor.

Sensor and Target interaction: In the case of an EC sensor coupled with a conductive plate, it is known that the $\mathrm{NI}$ of the sensor, $Z_{n}$, is a function of the thickness, the electromagnetic parameters of the plate, and of the EC frequency. In our study, the $\mathrm{NI}$ of the sensor coupled with the multilayered structure, denoted $Z_{n t}$, is likely to be a related to the coating thickness $c$, the rib thicknesses $r$ and to the air gap $a$, and is expected to be advantageously studied in the $\mathrm{NI}$ plane which plots the normalized reactance of the sensor as a function of the normalized resistance. Therefore, our experiment is implemented to measure the $\mathrm{NI}$ of the sensor over a large frequency range (from 80 to $30 \mathrm{kHz}$ ). We define a NI distance $d$ of $Z_{n t}$, as:

$$
d=\left|Z_{n t}(f)-Z_{n 0}(f)\right|
$$

where $Z_{n o}$ denotes the $\mathrm{NI}$ of the sensor obtained when the coating and the rib are in contact (i.e. $a=0$ ), and $Z_{n t}$ the $\mathrm{NI}$ obtained when the air-gap $a$ is nonzero.

The experiments show that an affine relation relates $d$ to a (3), provided that the frequency $f$ does not exceed a maximum value $f_{\max }$ approximately equal to the frequency at which the skin depth $\delta$ of the induced EC equals $2 / 3$ of the coating thickness $c$.

$$
d(a)=\alpha(f, c, r) \cdot a
$$

Further analysis of the experimental results also shows that an optimal frequency $f_{\text {opt }}$ exists, that maximizes the slope of the $d(a)$ curves, whatever the 
value of a (Fig. 2). This frequency is approximately that for which the skin depth $\delta$ of the EC is 2.5 times the coating thickness $c$. It is worth noting that in the $\left[f_{\text {opt }} f_{\text {max }}\right]$ interval, the normalized impedance distance decreases as the excitation frequency increases (Fig. 2). One can also notice that for a fixed coating thickness and a fixed excitation frequency, the thicker the rib the higher the NI distance $d$.

Finite elements computations: Finite Elements (FE) computations were carried out to further investigate the $d(a)$ relationships. To do so, a large variety of structures and EC frequencies were considered and simulated using finite elements (FE) modelling implemented by means of the commercial software ANSYS. The obtained computed database was used to verify the relationship (3). As shown in Fig. 3, which compares experimental results to the corresponding simulations, the simulations are in good agreement with the measurements and, as expected, the simulated $d$ vary linearly as a function of the air gap $a$.

Conclusion: The linear relationship between $d$ and a was brought to light by analysing the physical interaction between an EC sensor and a multilayered structure, both starting from experimental and computed data. These results open the way to the design of simple multi-frequency model-based approaches to solve the inverse problem of the EC NDE of aeronautical assemblies. 


\section{References}

1 LE DIRAISON, Y., JOUBERT, P.Y., PLACKO, D. : 'Characterization of subsurface defects in aeronautical riveted lap-joints using multi-frequency eddy current imaging', NDT\&E international, 2009, vol. 42, pp. 133-140

2 VERNON, S.N. : 'The universal impedance diagram of the ferrite pot core eddy current transducer', IEEE Trans. Magnetic, 1999, vol. 25, no.3, pp. 2639-2645

3 HUANG, P., ZHANG, G., WU, Z., CAI, J., ZHOU, Z., 'Inspection of defects in conductive multi-layered structures by an eddy current scanning technique: simulation and experiments', NDT\&E international, 2006, vol. 39, pp. 578-584

4 RENAKOS, I.T., THEODOULIDIS, T.P., PANAS,S.M., TSIBOUKIS, T.D. : 'Impedance inversion in eddy current testing of layered planar structures via neural networks', NDT\&E international, 1997, vol. 30, pp. 69-74

5 HUANG, P., ZHANG, G., HOU, D., ZHOU, Z., WU, Z., 'Modeling and inversion techniques for thickness measurement of multi-layered structures in eddy current testing', Insight, Jul. 2006, vol. 48, no. 7, pp. 406-409

6 TAFLOVE, A.: 'Computational electrodynamics' (Artech House, Norwood, MA, 1995)

\section{Authors' affiliations:}

T.L. Cung, P.Y. Joubert, E. Vourch and P. Larzabal, SATIE, ENS Cachan, CNRS,UniverSud, 61 Avenue du Président Wilson, 94235 Cachan Cedex, France 


\section{Figure captions:}

Fig. 1 Experimental setup: EC sensor on a coating/air-gap/rib aeronautical layered structure.

Fig. 2 Evolution of the $\mathrm{NI}$ distance $d$ as function of the excitation frequency $f$.

Fig. 3 Affine relationship $d(a)$ in the case where $c=r=1.5 \mathrm{~mm}$, obtained from FE simulations and from EC experiments, at frequencies $1 \mathrm{kHz}$ and $2.2 \mathrm{kHz}$. 
Figure 1

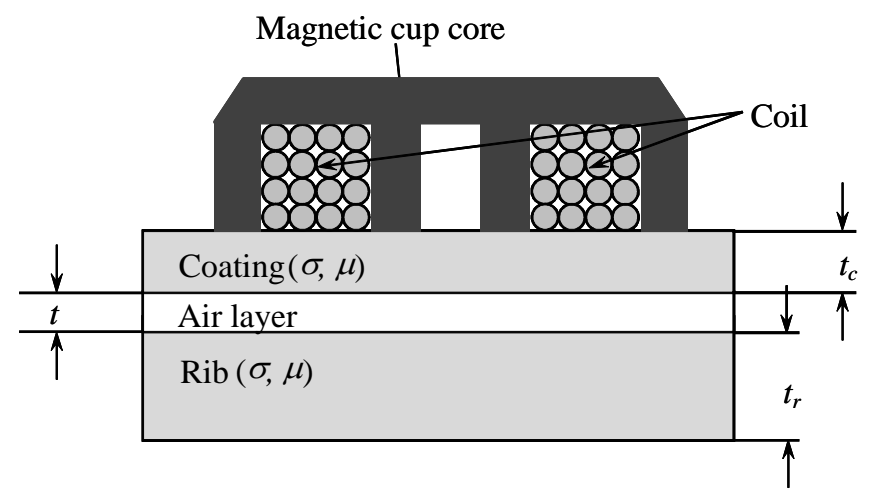


Figure 2

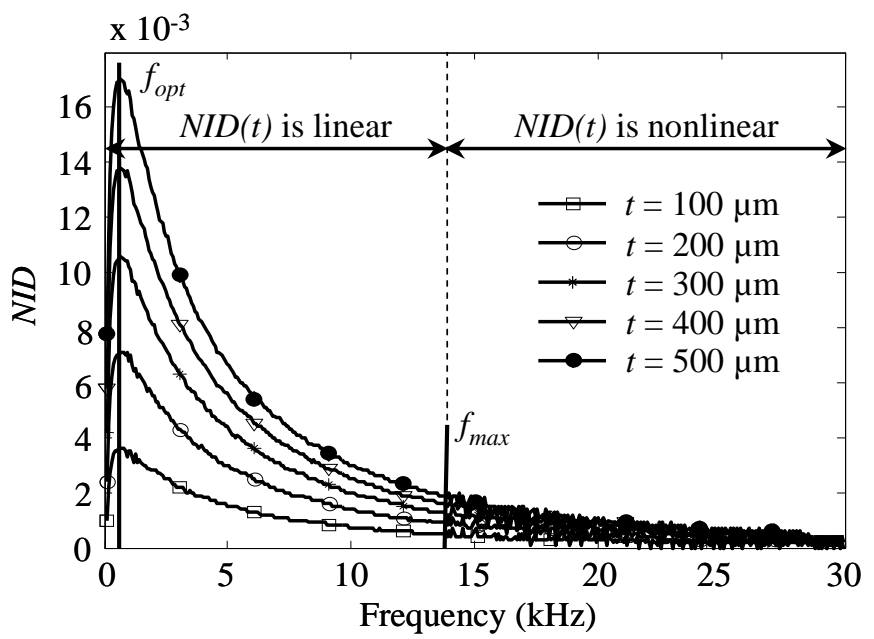


Figure 3

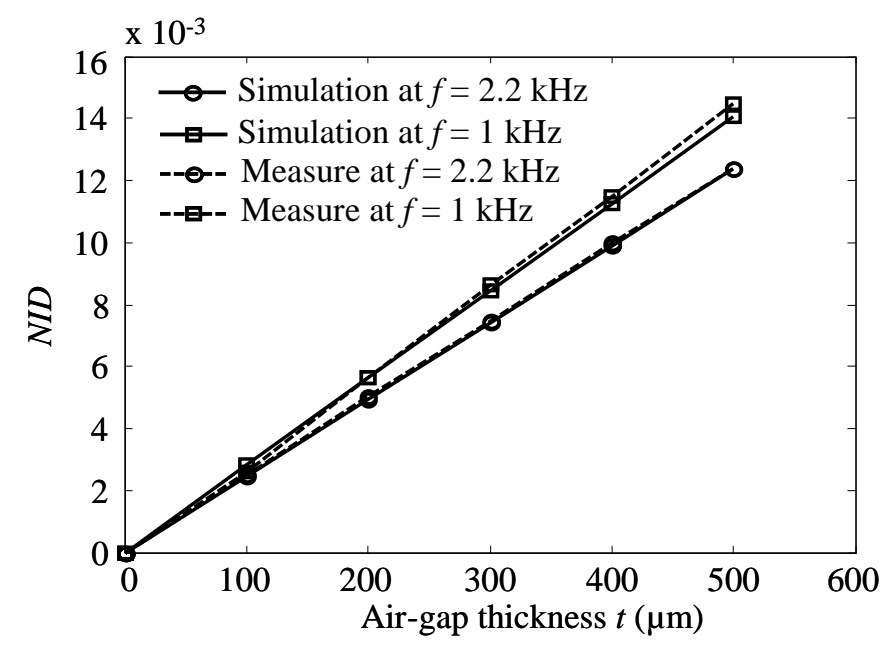

